\title{
Community-acquired pneumonia in children: A multidisciplinary consensus review
}

\author{
Donald E Low MD FRCPC ${ }^{1}$, James D Kellner MD MSc FRCPC ${ }^{2}$, Upton Allen MB MSc FAAP FRCPC ${ }^{3}$, \\ Francois D Boucher MD FRCPC ${ }^{4}$, Thomas Kovesi MD FRCPC ${ }^{5}$, John Reisman MD FRCPC ${ }^{5}$, \\ Ross Davidson $\mathrm{PhD}^{6}$, Joanne M Langley MD MSC FRCPC ${ }^{7}$
}

\begin{abstract}
DE Low, JD Kellner, U Allen, et al. Community-acquired pneumonia in children: A multidisciplinary consensus review. Can J Infect Dis 2003;14(Suppl B):3B-11B.

Community-acquired pneumonia (CAP) is common among children and may have viral, bacterial or, occasionally, other causes. The etiology is complex, with age-related trends, and differs from that in adult CAP, necessitating different management guidelines. There is an absence of current guidelines for the management of pediatric CAP (PCAP) that take into account changing etiologies, antimicrobial-resistance issues and the use of newly licensed antimicrobials. The present review does not provide specific guidelines, but it reviews the literature and presents currrent approaches to the treatment of PCAP. To compile the review, an expert panel was convened to provide a consensus. The review discusses the etiology, diagnosis and antimicrobial treatment of PCAP as well as indications for referral to a hospital emergency department. The goal of the review is to provide those involved with treatment of PCAP in the community setting with information that can be used to make effective treatment choices.
\end{abstract}

Key Words: Evidence-based review; Pediatric CAP; Treatment

\section{Pneumonie extra-hospitalière chez les enfants : consensus pluridisciplinaire}

La pneumonie extra-hospitalière $(\mathrm{PEH})$ n'est pas rare chez les enfants et elle peut avoir une cause virale, bactérienne ou autre, parfois. Son étiologie est complexe, montre des tendances liées à l'âge et diffère de celle de la PEH chez l'adulte, d'où la nécessité d'avoir des lignes directrices propres à son traitement. Toutefois, il n'existe actuellement aucune ligne de conduite relative au traitement de la PEH chez les enfants, qui tienne compte des différences d'étiologie, de la résistance aux antimicrobiens et de l'utilisation des agents nouvellement approuvés. Le présent examen ne fournit pas de lignes directrices particulières; il fait plutôt état de la recherche documentaire sur le sujet et des différentes démarches thérapeutiques mises en œuvre chez les enfants. Pour ce faire, on a formé un groupe de travail qui avait pour tâche d'élaborer un consensus. Il s'est penché sur l'étiologie, le diagnostic et le traitement antimicrobien de la PEH en pédiatrie ainsi que sur les indications de renvoi au service d'urgence d'un centre hospitalier. L'examen avait pour but de fournir à ceux qui travaillent en milieu communautaire de l'information pertinente sur le traitement de la $\mathrm{PEH}$ chez les enfants afin de leur permettre de prendre des décisions éclairées en la matière.
$\mathrm{P}$ ediatric community-acquired pneumonia (PCAP) is an acute infection of the pulmonary parenchyma acquired outside of a hospital setting. It is a common illness both in North America and in the developing world. Every year, an estimated four million deaths due to acute respiratory tract infections, mostly pneumonia, occur worldwide in children under five years of age (1). In the United States, childhood mortality rates from pneumonia have fallen by $97 \%$ over the past 50 years, likely due to improved nutrition, wider access to acute medical care and the use of antimicrobial agents (2). In addition, immunization against agents associated with lower respiratory tract infections such as measles, Streptococcus pneumoniae, Bordetella pertussis and Haemophilus influenzae type b (Hib) has contributed to the decreasing incidence. The frequency of pneumonia decreases with age; $80 \%$ of all pneumonia episodes occur in children under the age of seven years, with the peak attack rate in children aged two to four years (3). In 2000, a seven-valent pneumococcal polysaccharide-protein conjugate vaccine became available, which, unlike the previous 23-valent vaccine, showed protection in children under the age of two years and will likely contribute to changes in the etiology of PCAP (4-6).

\footnotetext{
${ }^{1}$ Toronto Medical Laboratories and the University of Toronto, Toronto, Ontario; ${ }^{2}$ University of Calgary and Alberta Children's Hospital, Calgary, Alberta; ${ }^{3}$ University of Toronto and Hospital for Sick Children, Toronto, Ontario; ${ }^{4}$ Université Laval and Centre Hospitalier Universitaire de Québec (CHUL), Quebec City and Sainte-Foy, Québec; ${ }^{5}$ Department of Pediatrics, Children's Hospital of Eastern Ontario, Ottawa, Ontario; ${ }^{6}$ Queen Elizabeth II Health Sciences Centre and Dalhousie University, Halifax, Nova Scotia; ${ }^{7}$ Clinical Trials Research Center, IWK Health Center and Dalhousie University, Halifax, Nova Scotia

Correspondence: Dr DE Low, Room 1479, Mount Sinai Hospital, 600 University Avenue, Toronto, Ontario M5G 1X5. Telephone 416-586-4435, fax 416-586-8746, e-mail dlow@mtsinai.on.ca

Reprints: Core Health Services Inc., 1800 Steeles Avenue West, Second Floor, Concord, Ontario L4K 2P3
} 
There are several guidelines for the management of pneumonia in adults (7-9). However, data derived from the adult pneumonia setting cannot be applied directly to pediatric pneumonia, partly as a consequence of the structural differences between the immature and mature respiratory tracts and the differences among etiological agents. The Canadian guidelines for pediatric pneumonia published in 1997 (10) were the first comprehensive guidelines to address treatment of pneumonia in children. Since then, the roles of Chlamydia pneumoniae and Mycoplasma pneumoniae in the etiology of pneumonia have been further elucidated, antimicrobial resistance patterns have continued to change and several new agents have been approved for use in children. Hence, a Working Group, made up of Canadian physicians from several different fields of expertise including pediatric respirologists, infectious disease specialists and microbiologists undertook to compile a consensus review. The goal was to provide up-to-date information on pediatric pneumonia in the ambulatory setting, in immunocompetent children older than one month without underlying cardiorespiratory disease, such that management of disease in these children could be undertaken more successfully.

The review is based on a comprehensive literature search. Relevant articles cited in the previously published guidelines were obtained. An additional Medline search for relevant articles published between 1996 and March 2003 was performed. The MeSH search terms included "pneumonia", "respiratory tract infections", "pneumonitis", "etiology", "diagnosis", "therapy", "management", "antibiotics", "resistance", "radiology", "microbiology" and "biochemistry". The etiology, physical diagnosis, laboratory investigations and therapy of PCAP are reviewed. The present review is not intended as a practice guideline for treatment of PCAP, and specific recommendations based on grades of evidence have not been provided (ie, $A=$ good evidence to support a recommendation for use; $\mathrm{B}=$ moderate evidence to support a recommendation; $\mathrm{C}=$ poor evidence to support a recommendation; $\mathrm{D}=$ moderate evidence to support a recommendation against use; $\mathrm{E}=$ good evidence to support a recommendation against use) (11). However, the quality of evidence has been graded, where possible, using the Infectious Disease Society of America grading system for assessing levels of evidence $(11,12)$. Level 1 represents data obtained from one or more properly randomized controlled trials. Level II represents evidence from the following: one or more well-designed clinical trials without randomization; cohort or case-controlled studies; data obtained from multiple time-series; or dramatic results from uncontrolled experiments. Level III represents evidence from the opinions of respected authorities based on clinical experience, descriptive studies or reports of expert committees.

\section{ETIOLOGY OF PNEUMONIA}

Identifying the etiology of pneumonia is much more difficult in infants and young children than in older children and adults due to the difficulty of obtaining a lower respiratory tract secretion and because invasive methods of diagnosis cannot be routinely used. If a respiratory specimen is obtained, the paucity of rapid diagnostic tests affects management because these tests are usually insensitive or not easily available to the practicing physician caring for the child with pneumonia. Blood cultures have a low sensitivity (below 20\%) and have been shown to be dependent on disease severity (Level I and II evidence) (13-15). In a prospective study of 136 children with PCAP hospitalized in the United Kingdom, the most useful laboratory diagnostic tests were found to be serology and viral immunofluorescence (Level II evidence) (16). Direct immunofluorescence tests and enzyme-linked immunosorbent assays for viruses are becoming more readily available in most Canadian pediatric centres. Serology has been used in the diagnosis of $\mathrm{M}$ pneumoniae and $\mathrm{C}$ pneumoniae infections, and in research settings to document the epidemiology of more common respiratory pathogens such as $\mathrm{S}$ pneumoniae, $\mathrm{H}$ influenzae and Moraxella catarrhalis $(13,17-20)$. The polymerase chain reaction (PCR) is available in some Canadian centres to identify infection due to $\mathrm{B}$ pertussis, $\mathrm{C}$ pneumoniae, $M$ pneumoniae and respiratory viruses. However, serology, fluorescent assays and PCR are not always easily accessible to all primary caregivers and these tests have not always proved to be successful in establishing etiology. In one recent study (18), when extensive diagnostic testing was performed, the etiology was determined in $85 \%$ of cases (Level II evidence). However, in another study (13) using similar diagnostic tests, a pathogen was identified in only $43 \%$ of cases (Level I evidence). Such discrepancies have led to uncertainty as to the true prevalence of specific organisms.

Although various studies indicate that specific etiologies are influenced by the age of the child, some of these studies are flawed by the lack of testing for all possible agents. Nevertheless, there are consistent trends. Neonatal bacterial pathogens, often acquired from the genital tract of the mother, including Group B streptococci, enteric flora such as Escherichia coli and, less commonly, Listeria monocytogenes can sometimes cause pneumonia in the first three months of life (21). From three weeks to three months, Chlamydia trachomatis, respiratory syncytial virus (RSV), parainfluenza virus, S pneumoniae, B pertussis and Staphylococcus aureus are commonly found (22). In a Canadian study of 71 hospitalized infants less than six months of age, the cause of pneumonia was found to be a respiratory virus in $37 \%$ of cases, to $\mathrm{C}$ trachomatis in $17 \%$ of cases, and to $\mathrm{C}$ trachomatis and/or Ureaplasma urealyticum in 21\% of cases (Level II evidence) (20). C trachomatis is most commonly found in afebrile pneumonia patients who do not have wheezing whereas if wheezing is present, a viral etiology is more likely (20). C trachomatis and U urealyticum acquired perinatally can present as an afebrile pneumonitis up to 19 weeks of age (20).

Viruses are identified most often in children under the age of five years, with RSV being the most common (peak incidence two to seven months) (Level II evidence) $(18,23)$. Other respiratory viruses such as adenovirus, rhinovirus, parainfluenza and influenza virus have also been identified in younger children (22).

Bacterial pneumonia becomes more likely after six months of age, with $S$ pneumoniae being the most commonly identified bacterial cause of pneumonia in all age groups (Levels I and II evidence) $(13,18,19)$. Pneumonia caused by Group A Streptococcus, S aureus and H influenzae 
is less frequent. Hib bacteremia in association with pneumonia has been almost eliminated in Canada since the introduction of universal infant immunization programs, and hospitalization for $\mathrm{x}$-ray positive pneumonia has decreased by $30 \%$ in children under the age of two years following Hib vaccination (24-26). However, strains of other serotypes or nontypeable strains may cause infection. Dual infections, mostly concomitant viral and bacterial infections, have been noted in several studies to account for up to $30 \%$ of cases (Level II evidence) $(18,20,23,27)$.

Until recently, $M$ pneumoniae and $C$ pneumoniae were not thought to cause pneumonia in children before the age of five years. However, studies using molecular diagnostic techniques on respiratory tract specimens have shown that younger children are also at risk, although less so than children over five years of age. In a study of 70 children on the Indian subcontinent under the age of five years with acute respiratory tract infections, $M$ pneumoniae and $C$ pneumoniae infection were seen in 30\% and 3\% of cases, respectively (Level III evidence) (28). In Italy, the prevalence of $\mathrm{M}$ pneumoniae and $\mathrm{C}$ pneumoniae in 196 children aged two to five years was $15 \%$ and $3 \%$, respectively (Level III evidence) (29). The frequency of pneumonia due to these organisms increases with age. Diagnostic serology identified $42 \%$ of children between the ages of five and nine years and $67 \%$ of children over the age of 10 years to have pneumonia due to $\mathrm{M}$ pneumoniae and $\mathrm{C}$ pneumoniae, with the latter more commonly isolated in the older age group (Level II evidence) (30).

Pneumonia due to less common etiological agents may also occur in some groups. Tuberculosis infection in children may sometimes present as pneumonia. Although Canada has one of the lowest reported rates of tuberculosis in the world, cases of tuberculosis are still seen in all groups of patients. However, a high incidence of disease is reported in some Canadian Aboriginal communities, in inner city populations, and in children of immigrants or refugees from high-incidence areas such as Africa, Asia, Latin America, the Caribbean and the Middle East (31). In children with these risk factors and signs of lower respiratory tract disease, the diagnosis of Mycobacterium tuberculosis must be pursued. Nonspecific signs predominate in young children, but in the child older than six years, a localized pleural effusion may occur with cough, chest pain, tachypnea and fever.

Insidious or acute onset Pneumocystis carinii pneumonia may be the first clinical illness in infants with unrecognized HIV infection acquired during the perinatal period. $P$ carinii pneumonia most commonly presents between ages three to six months but can occur as early as four weeks of age and has a high mortality. Pneumonia may also occur in children with unsuspected congenital immune deficiency. The management of children with pneumonia and known immunosuppression is beyond the scope of this review.

\section{CLINICAL ASSESSMENT}

Pneumonia is an infection of the pulmonary parenchyma. Consolidation of airspaces results in inadequate air exchange, which presents clinically as respiratory distress and increased work of breathing. Signs of respiratory
TABLE 1

Age-specific criteria for tachypnea

\begin{tabular}{lcc}
\hline Age & $\begin{array}{c}\text { Approximate normal } \\
\text { respiratory rates } \\
\text { (breaths/min) }\end{array}$ & $\begin{array}{c}\text { Tachypnea threshold } \\
\text { (breaths/min) }\end{array}$ \\
\hline$<2$ months & $34-50$ & 60 \\
$2-12$ months & $25-40$ & 50 \\
$1-5$ years & $20-30$ & 40 \\
$>5$ years & $15-25$ & 20 \\
\hline
\end{tabular}

Data from references 36 and 37

distress including tachypnea, subcostal retractions, cough, crackles and decreased breath sounds should be considered as possible predictors of pneumonia. The predictive value of these signs is greater if more than one is present and if the child is febrile or cyanotic (32). The best predictor of pneumonia in children is tachypnea (Level II evidence) (33). In febrile children up to two years of age, the presence of tachypnea has a $70 \%$ sensitivity and a $40 \%$ to $70 \%$ specificity that pneumonia is present (Level II evidence) $(34,35)$. However, in children with a disease duration of less than three days, tachypnea has only a 55\% sensitivity (35). Age-specific criteria for tachypnea are shown in Table 1 $(36,37)$. The clinician should document the respiratory rate by observing the child in a calm or sleeping state for $60 \mathrm{~s}$, because shorter observation periods will yield falsely elevated readings (38). When neither tachypnea, respiratory distress, crackles nor reduced breath sounds are present, chest radiographs are unlikely to be positive (Level II evidence) $(33,38)$.

Presence of fever (temperature greater than two standard deviations above age-related norms) is also a good screen for pneumonia, with a reported sensitivity of $94 \%$ and a negative predictive value of 97\% (Level II evidence) (39). Assessment of oxygenation by pulse oximetry in the child with distress is valuable because oxygenation gives a good indication of the severity of disease (40), and the respiratory rate does not correlate well with oxygenation (37). In pneumonia, cyanosis is a late and uncommon sign indicating severe hypoxia $(37,40)$.

In assessing the severity of pneumonia, overall clinical appearance and behaviour including alertness and willingness to accept food should be taken into consideration. Subcostal retractions and other evidence of laboured breathing increase the likelihood of a more severe form of pneumonia (Level III evidence) (36).

In a small proportion of children under five years of age, pneumonia cannot always be accurately diagnosed based on the presence or absence of clinical findings specific to the respiratory tract (38). Some signs like crackles and wheezing can be present in other lower respiratory tract diseases, such as bronchiolitis and asthma, or may be due to transmitted sounds from the upper airway. Conversely, no auscultatory signs may be present in the infant with a bacterial lobar pneumonia. In a study of 146 febrile children under the age of five years with leukocytosis and no clinical evidence of pneumonia or other major infectious source, a chest radiograph revealed pneumonia in 26\% of the children (41). Also, in acutely ill and febrile children, pneumonia may present as pain referred to the abdomen $(42,43)$. 


\section{RADIOLOGICAL ASSESSMENTS}

There is no clear consensus as to when a chest radiograph is necessary. Although chest radiographs are useful in some isolated cases, they have not consistently been shown to influence management decisions or to significantly affect time to recovery (Level I evidence) $(44,45)$. Chest radiographs are useful only when clinical findings are ambiguous, when a complication such as a pleural effusion is suspected, or when pneumonia is prolonged and unresponsive to antimicrobials (Level II evidence) $(46,47)$. However, because no auscultatory signs may be present in a proportion of febrile children with leukocytosis (41), chest radiography should be considered in children under the age of five years without an alternative major source of infection but with a temperature of $39^{\circ} \mathrm{C}$ or higher, and a white blood cell (WBC) count of $20 \times 10^{9} / \mathrm{L}$ or higher. In general, the perceived need for a chest radiograph is likely to be determined by the clinician's experience in auscultating a child's chest and the level of comfort that the clinician has in arriving at a diagnosis $(48,49)$. Further, there appears to be considerable interobserver variability in the diagnosis of pneumonia from a chest radiograph (50).

Chest radiographs have not been reliably shown to distinguish viral from bacterial pneumonia (Level II evidence) $(23,46,51,52)$. However, there is evidence of their usefulness in distinguishing between pneumonia and bronchiolitis. In a study of 522 children aged two to 59 months randomly allocated to have a chest radiograph, pneumonia and upper respiratory tract infections were diagnosed more often and bronchiolitis less often in the chest radiograph group (Level I evidence) (44). In the wheezing child, a chest radiograph is more likely to yield a potentially clinically significant finding such as an infiltrate or air leak, when fever or localized findings are also present, or when there is no family history of asthma (53). In the absence of persisting symptoms or signs, a follow-up chest radiograph performed one month after the initial diagnosis is unlikely to demonstrate clinically significant findings (54) and need not be obtained.

\section{LABORATORY ASSESSMENTS}

The use of laboratory data to confirm the diagnosis of pneumonia is hampered by the difficulty of obtaining a lower respiratory tract specimen in children. Children under seven years of age usually cannot produce sputum, and if they do, it is likely to be a specimen contaminated with normal oral and respiratory flora. Cultures of nasopharyngeal swabs for bacterial identification are not of value, and most laboratories will only process such specimens for the presence or absence of Group A streptococcus causing pharyngitis. Although culture of lung aspirates in children who have not received antibiotics can determine bacterial etiology $(55,56)$, this procedure is considered too invasive and is rarely used today. Blood cultures, although accurate in determining bacterial etiology, have a low sensitivity (less than 20\%) (Levels I and II evidence) $(13-15,18)$ and may not be useful in the outpatient setting. However, they should be performed on any child with more severe pneumonia requiring hospital care who is febrile, and in young infants (eg, less than three months of age) (57). If sputum is available, Gram stain of high quality samples (fewer than
10 squamous epithelial cells and greater than $25 \mathrm{WBCs} / \mathrm{low}$ power field) can assist in diagnosis. In children with pleural effusions, cultures before antibiotic therapy have been found to be of benefit in determining bacterial etiology (58). A WBC count of greater than $15 \times 10^{9} / \mathrm{L}$ to $20 \times 10^{9} / \mathrm{L}$ and a temperature of higher than $39^{\circ} \mathrm{C}$ is suggestive of bacterial infection in a child under the age of five years $(10,57,59)$.

Many laboratories offer viral culture and immunofluorescence assays for viruses such as influenza and RSV. Some laboratories also offer rapid PCR tests for respiratory viruses (eg, RSV), which have a specificity and sensitivity of greater than $95 \%$ and can be performed on nasopharyngeal aspirates (60). However, neither cultures nor serological testing for specific pathogens such as $\mathrm{M}$ pneumoniae or $\mathrm{C}$ pneumoniae are recommended routinely for the diagnosis of outpatient pneumonia in children. These and other tests such as viral cultures, detection of viral antigens and cold agglutinins are useful only when the results might alter management (61). Depending on the age of the patient, the severity of disease and epidemiological factors (eg, exposure of young infants to pertussis), such testing may be helpful if available. For example, a positive rapid immunofluorescence test for RSV in an infant with characteristics of bronchiolitis would confirm the diagnosis of viral bronchiolitis and rule out, in the vast majority of cases, bacterial pneumonia.

\section{TREATMENT CONSIDERATIONS}

Clinical management of the child with suspected lower respiratory tract infection is directed toward identification of those who would benefit from antimicrobial therapy and those who might require admission to hospital. Hospital admission is necessary for children who need respiratory therapy or support, intravenous antimicrobials or in whom there is an inability to maintain oral hydration.

\section{Antimicrobial therapy}

An infectious etiology is not found in a significant proportion of PCAP cases, and even when the etiology is determined, a bacterial cause may only be associated with $50 \%$ or less of cases (Level II evidence) (62). Thus, the clinician who decides that antimicrobial treatment is warranted must choose an empirical treatment approach (63). The presence of symptoms and signs of sepsis, even in the absence of severe respiratory symptoms, suggests bacterial infection (22). Localized chest pain signifies pleural irritation that, in an otherwise healthy child, is indicative of bacterial pneumonia (22). Epidemiological factors are also useful considerations in predicting etiology, because RSV and influenza virus are mostly found in the winter and spring seasons.

In children who appear likely to have uncomplicated viral pneumonia and relatively mild disease, careful observation rather than antimicrobial therapy may be appropriate (64). Treatment should take into account the age of the child as well as clinical and epidemiological factors and, finally, the results of the chest radiograph (22).

Randomized controlled trials of antibiotic treatment for pneumonia in children do not use placebo, making it difficult to determine the relative benefits of treatment compared with no treatment. In general it is recommended 
that antibiotics be considered for children with clinical features of pneumonia when a bacterial cause is considered likely and if a chest radiograph is positive showing infiltrates or consolidation. However, the child who has RSV bronchiolitis may not need an antimicrobial even if the chest radiogram shows an infiltrate (65). Antibiotics are not recommended for the treatment of asthma excerbations in children, because the vast majority of exacerbations are triggered by viral infections. Severe asthma exacerbations have sometimes been associated with Mycoplasma and Chlamydia infections, and in such cases treatment with appropriate antibiotics should be considered (66).

\section{Antibiotic resistance}

Because antimicrobial therapy is empirical for the most part, one of the issues to be considered is the growing problem of antimicrobial resistance and, thus, knowledge of local, prevailing resistance patterns may be helpful in guiding empirical therapy.

The prevalence of penicillin-nonsusceptible $S$ pneumoniae strains can vary dramatically from country to country and even from region to region. In Canada, the overall prevalence of resistant strains according to region ranges from approximately $7 \%$ to $20 \%$, with a national mean of $13 \%$ (67). In a study of Canadian children attending daycare centres in the Toronto region in 1999, 44\% were colonized with S pneumoniae strains of which $17 \%$ were nonsusceptible to penicillin and 3\% were highly resistant (68). In another earlier study involving 11 pediatric tertiary care centres across Canada, $6.8 \%$ of isolates were nonsusceptible to penicillin with $1.7 \%$ showing highlevel resistance (69). The most dramatic change observed in Canada over the past five years has been the increase in the ratio of intermediately resistant $S$ pneumoniae strains (penicillin minimum inhibitory concentration [MIC] 0.12-1 mg/L) to high-level resistant strains (penicillin MIC $2 \mathrm{mg} / \mathrm{L}$ or greater) (67,70). A US study of pediatric pneumonia isolates demonstrated a significant increase in penicillin-intermediate and highly resistant strains and ceftriaxone intermediately resistant strains between 1993 and 1999 (71). Of concern is the disproportionate loss of activity among the oral cephalosporins observed in penicillin-nonsusceptible strains (67). Also associated with penicillin resistance is resistance against other unrelated antimicrobial classes $(67,68,72)$. The prevalence of these multidrug-resistant strains has increased steadily in Canada. In 1999, 6.7\% of $S$ pneumoniae strains were resistant to the macrolides in vitro, and rates of resistance to tetracycline and trimethoprim/sulfamethoxazole were $6.9 \%$ and $11.6 \%$, respectively (72).

In $H$ influenzae, beta-lactam resistance is mediated through the production of a beta-lactamase. Although five years ago, more than $40 \%$ of $\mathrm{H}$ influenzae strains produced a beta-lactamase, rendering them resistant to the aminopenicillins, the current prevalence of beta-lactamase-producing strains has decreased to 20\% (73). M catarrhalis, on the other hand, is considered to be uniformly resistant to ampicillin, because more than $95 \%$ of all strains are beta-lactamase producers, but is generally susceptible to all other agents (74).

\begin{tabular}{|c|c|c|}
\hline$\overline{\text { Age }}$ & Preferred therapy & Alternate therapy \\
\hline 1 to 3 months* & Macrolides $^{\dagger}$ & \\
\hline $\begin{array}{l}4 \text { months } \\
\text { to } 5 \text { years }\end{array}$ & $\begin{array}{l}\text { Amoxicillin or } \\
\text { amoxicillin/clavulanic } \\
\text { acid }\end{array}$ & $\begin{array}{l}\text { Macrolides } \\
\text { Second generation } \\
\text { cephalosporins }\end{array}$ \\
\hline 5 to 18 years & Macrolides & $\begin{array}{l}\text { Amoxicillin } \\
\text { Amoxicillin/clavulanic } \\
\text { acid } \\
\text { Second generation } \\
\text { cephalosporin } \ddagger\end{array}$ \\
\hline
\end{tabular}

*Outpatient therapy may not be appropriate for children less than three months of age if certain clinical signs such as fever and hypoxia are present. ${ }^{+}$Clarithromycin or azithromycin may be preferred over erythromycin for infants less than six months of age due to concerns regarding hypertrophic pyloric stenosis in this age group. ${ }^{\ddagger}$ These agents are not effective against Mycoplasma pneumoniae or Chlamydia pneumoniae

\begin{tabular}{|c|c|c|}
\hline Antibiotic & $\begin{array}{l}\text { Recommended } \\
\text { daily dosage }\end{array}$ & Frequency \\
\hline Amoxicillin & $\begin{array}{l}80 \mathrm{mg} / \mathrm{kg} \text { (if pen resistant only; } \\
\text { otherwise standard dosing: } \\
40 \mathrm{mg} / \mathrm{kg} \text { ) }\end{array}$ & TID \\
\hline $\begin{array}{l}\text { Amoxicillin/ } \\
\text { clavulanic acid }\end{array}$ & $\begin{array}{l}80 \mathrm{mg} / \mathrm{kg} \text { of amoxicillin } \\
\text { component (as above) }\end{array}$ & BID/TID \\
\hline Azithromycin & $\begin{array}{l}10 \mathrm{mg} / \mathrm{kg} \text { on day } 1 \text {, then } \\
5 \mathrm{mg} / \mathrm{kg} / \text { day for } 4 \text { days }\end{array}$ & Daily \\
\hline Cefprozil & $30 \mathrm{mg} / \mathrm{kg}$ & BID \\
\hline Cefuroxime axetil & $15 \mathrm{mg} / \mathrm{kg}$ & BID \\
\hline Clarithromycin & $15 \mathrm{mg} / \mathrm{kg}$ & BID \\
\hline $\begin{array}{l}\text { Erythromycin } \\
\text { (estolate) }\end{array}$ & $40-50 \mathrm{mg} / \mathrm{kg}$ & TID \\
\hline
\end{tabular}

BID Twice daily; pen Penicillin; TID Three times daily

Empirical antimicrobial therapy

Treatment regimens for pediatric pneumonia are based on the clinical situation, the most likely bacterial etiological agent and antimicrobial susceptibility data for the usual pathogens. Three studies $(13,75,76)$ have compared the efficacy of conventional therapy with amoxicillin, amoxicillin/clavulanate or an oral cephalosporin with that of azithromycin or clarithromycin. The results showed similar effectiveness among these agents, with excellent cure rates for each of the antibiotics included in the trials, and acceptable adverse events (Level I evidence). Despite the possibility of beta-lactamase-producing $\mathrm{M}$ catarrhalis and $\mathrm{H}$ influenzae and penicillin-resistant $S$ pneumoniae, amoxicillin is still an effective first-line therapy for most children with CAP thought to be of bacterial etiology. Should the child worsen or fail to improve on amoxicillin, consideration can be given to the use of higher doses in the case of penicillinresistant $S$ pneumoniae, or the use of beta-lactamase-resistant agents such as amoxicillin/clavulanic acid, or secondgeneration cephalosporins (Level III evidence). 


\section{TABLE 4}

Antimicrobial outpatient therapy for pediatric pneumonia by pathogen

\begin{tabular}{ll}
\hline Pathogen & Preferred therapy \\
\hline Streptococcus pneumoniae sensitive to penicillin $(\mathrm{MIC}<0.1 \mu \mathrm{g} / \mathrm{mL})$ & Amoxicillin \\
$\begin{array}{l}\text { S pneumoniae resistant to penicillin }(\mathrm{MIC} \geq 0.1 \mu \mathrm{g} / \mathrm{mL}) \\
\text { Haemophilus influenzae type b sensitive to ampicillin }\end{array}$ & Amoxicillin (high dose) \\
H influenzae type b resistant to ampicillin & Amoxicillin \\
& Amoxicillin/clavulanic acid or second-generation cephalosporin \\
Staphylococcus aureus & or azithromycin or clarithromycin \\
Streptococcus pyogenes & Cloxacillin \\
Mycoplasma pneumoniae & Penicillin \\
Chlamydia pneumoniae & Macrolide
\end{tabular}

MIC Minimum inhibitory concentration

Recommendations and dosage regimens for empirical antimicrobial therapy are listed in Tables 2 and 3, respectively. Because $S$ pneumoniae is the most common bacterial cause of pneumonia in children under five years of age, beta-lactam antibiotics are the first-line agents. High dose amoxicillin $(80 \mathrm{mg} / \mathrm{kg} / \mathrm{day})$ or amoxicillin/clavulanic acid may be appropriate if penicillin-resistant $S$ pneumoniae is suspected based on local prevalence rates; otherwise, a regular dose (40 mg) will suffice (Level III evidence). If the patient is allergic to beta-lactam agents, or if therapy with these agents is not successful, consultation with a pediatric specialist is appropriate. The macrolides, erythromycin, azithromycin and clarithromycin should be considered as first-line agents in patients five years of age and older because of the increasing frequency of pneumonia caused by $\mathrm{M}$ pneumoniae and $\mathrm{C}$ pneumoniae (Level I evidence) $(77,78)$. Alternative choices in this age group include amoxicillin, amoxicillin/clavulanic acid and a variety of second-generation cephalosporins. However, none of these agents are effective against $M$ pneumoniae or C pneumoniae.

Patients on empiric therapy as well as those not on antibiotics because a viral cause was considered likely should be followed up within $24 \mathrm{~h}$ to $72 \mathrm{~h}$, either by phone or by return visit, to ensure that there is no deterioration and to confirm efficacy of treatment (Level III evidence).

\section{Pathogen-directed antimicrobial therapy}

If a specific bacterial etiological agent is isolated from a child with pneumonia, antimicrobial therapy may be directed specifically toward that agent. Table 4 describes the most appropriate antimicrobial therapy for the treatment of specific bacterial agents. Isolates from upper airways specimens should not be used to direct therapy because these will also contain normal respiratory tract flora. Antimicrobial agents are not recommended for treatment of viral pneumonia.

\section{Referral to a hospital emergency department}

Although various criteria have been used to determine the likelihood of a severe outcome in the case of adult patients with CAP (77), similar prediction rules do not exist for children. Tachypnea is used as a criterion by the World Health Organization to identify children who should be referred for medical assessment, and in addition, 'danger signs' such as inability to feed, seizures, lethargy or cyanosis predict which children need hospital care $(36,78)$. The physician's clinical judgement will play a major role in determining the need for referral to the emergency department for possible admission, diagnostic testing or specialist assessment. Some considerations for referral are outlined below (Level III evidence).

High-risk of a complicated outcome: During the first year of life the signs of respiratory disease may be subtle. In addition, the risk of a complicated outcome is highest among young infants as well as children with existing comorbidities. Extrapulmonary spread of infection rarely occurs, except in young infants, in whom meningitis or metatastic septic foci may occur with certain etiological types of pneumonia, notably $S$ aureus. Clinical judgement should be used in deciding whether or not infants aged less than three months with pneumonia need to be hospitalized, but those with fever or hypoxia indicate the need for a careful workup and are more likely to need hospitalization. Children requiring oxygen or intravenous therapy may be considered candidates for hospital admission.

Presence of comorbid conditions: The management of children with certain comorbid conditions (eg, immunodeficiency, cardiac or pulmonary disease) is beyond the scope of this review. These children may present with manifestations of more severe disease and deteriorate quickly. In this regard, supportive treatment may be needed in the form of oxygen therapy and respiratory support.

Presence of complications: Initial evaluation by the primary caregiver may reveal the presence of hypoxia, dehydration, circulatory collapse or respiratory failure, all of which indicate the need for resuscitation and emergent care. Presence of a complicated pneumonia such as pleural effusion, lung abscess and/or pneumatocele are also indications for hospitalization, as is evidence of extrapulmonary spread of infection, such as septic arthritis or meningitis.

Inability to administer therapy effectively: It may be necessary for some children to be referred for possible admission to hospital if the clinician has concerns about his or her ability to effectively treat the pneumonia on an outpatient basis. This may be due to several factors, including poor compliance, as well as the inability of the infant to tolerate oral therapy. The latter may be due to decreased oral intake and vomiting accompanying the pneumonia. 
Failed therapy: Children who have failed initial therapy should be referred for possible admission. Although not all of these children will require admission to hospital, some may require an initial period of parenteral therapy followed by a step-down to oral therapy.

Recurrent pneumonia: Children may have recurrent pneumonia for several reasons. These include the possibility of immunodeficiency states, mucociliary transport defects such as cystic fibrosis or immotile cilia syndrome, or recurrent aspiration. Some children with recurrent or persistent radiographic changes in a fixed location may have underlying mass lesions, congenital abnormalities or a foreign body. Bronchoscopy or other investigations may be required in these situations. Studies have shown that the most common cause of 'recurrent pneumonia' or 'recurrent bronchitis' in children is undiagnosed asthma (79). Children with recurrent pneumonia should be evaluated to determine whether they have asthma.

\section{CONCLUSIONS}

The etiology of CAP in children is complex and likely to change with the advent of improved vaccines against major pathogens. Breathing rate and other respiratory signs are usually good indicators of pneumonia, but in cases of uncertainty or if complications are present, a chest radiograph may help to confirm the diagnosis. Laboratory tests may distinguish between viral and bacterial pneumonia but are not always readily available, and some of the more common tests are neither timely nor accurate. However, where there is doubt, a combination of clinical signs together with results of the chest radiograph and laboratory tests can establish a diagnosis. These considerations can be used to determine the necessity for empiric antimicrobial treatment and prevailing antimicrobial susceptibility patterns should guide treatment choices.

ACKNOWLEDGEMENTS: The authors gratefully acknowledge the contribution of Dr Barbara Law and Dr Marc Lebel to the content and editing of the manuscript. Sponsored by an unrestricted educational grant from Pfizer Canada Inc. Preparation of this manuscript was coordinated by Core Health Services Inc.

\section{REFERENCES}

1. Mulholland K. Magnitude of the problem of childhood pneumonia. Lancet 1999;354:590-2.

2. Dowell SF, Kupronis BA, Zell ER, Shay DK. Mortality from pneumonia in children in the United States, 1939 through 1996. N Engl J Med 2000;342:1399-407.

3. Murphy TF, Henderson FW, Clyde WA Jr, Collier AM, Denny FW. Pneumonia: An eleven-year study in a pediatric practice. Am J Epidemiol 1981;113:12-21.

4. Shinefield HR, Black S. Efficacy of pneumococcal conjugate vaccines in large scale field trials. Pediatr Infect Dis J 2000;19:394-7.

5. Black SB, Shinefield HR, Ling S, et al. Effectiveness of heptavalent pneumococcal conjugate vaccine in children younger than five years of age for prevention of pneumonia. Pediatr Infect Dis J 2002;21:810-5.

6. Pelton SI, Dagan R, Gaines BM, et al. Pneumococcal conjugate vaccines: Proceedings from an interactive symposium at the 41st Interscience Conference on Antimicrobial Agents and Chemotherapy. Vaccine 2003;21:1562-71.

7. Mandell LA, Marrie TJ, Grossman RF, Chow AW, Hyland RH. Summary of Canadian guidelines for the initial management of community-acquired pneumonia: An evidence-based update by the Canadian Infectious Disease Society and the Canadian Thoracic Society. Can Respir J 2000;7:371-82.

8. Bartlett JG, Dowell SF, Mandell LA, File TM Jr, Musher DM, Fine MJ. Practice guidelines for the management of community-acquired pneumonia in adults. Infectious Diseases Society of America. Clin Infect Dis 2000;31:347-82.

9. Niederman MS, Mandell LA, Anzueto A, et al. Guidelines for the management of adults with community-acquired pneumonia. Diagnosis, assessment of severity, antimicrobial therapy, and prevention. Am J Respir Crit Care Med 2001;163:1730-54.

10. Jadavji T, Law B, Lebel MH, Kennedy WA, Gold R, Wang EE. A practical guide for the diagnosis and treatment of pediatric pneumonia. CMAJ 1997;156:S703-11.

11. Kish MA. Guide to development of practice guidelines. Clin Infect Dis 2001;32:851-4.

12. Woolf SH, Battista RN, Anderson GM, Logan AG, Wang E. Assessing the clinical effectiveness of preventive maneuvers: Analytic principles and systematic methods in reviewing evidence and developing clinical practice recommendations. A report by the Canadian Task Force on the Periodic Health Examination. J Clin Epidemiol 1990;43:891-905.

13. Wubbel L, Muniz L, Ahmed A, et al. Etiology and treatment of community-acquired pneumonia in ambulatory children. Pediatr Infect Dis J 1999;18:98-104.

14. Waterer GW, Wunderink RG. The influence of the severity of community-acquired pneumonia on the usefulness of blood cultures. Respir Med 2001;95:78-82.

15. Delport SD, Brisley T. Aetiology and outcome of severe community-acquired pneumonia in children admitted to a paediatric intensive care unit. S Afr Med J 2002;92:907-11.

16. Drummond P, Clark J, Wheeler J, Galloway A, Freeman R, Cant A. Community acquired pneumonia - A prospective UK study. Arch Dis Child 2000;83:408-12.

17. Principi N, Esposito S, Blasi F, Allegra L. Role of Mycoplasma pneumoniae and Chlamydia pneumoniae in children with community-acquired lower respiratory tract infections. Clin Infect Dis 2001;32:1281-9.

18. Juven T, Mertsola J, Waris M, et al. Etiology of communityacquired pneumonia in 254 hospitalized children. Pediatr Infect Dis J 2000;19:293-8.

19. Vuori E, Peltola H, Kallio MJ, Leinonen M, Hedman K. Etiology of pneumonia and other common childhood infections requiring hospitalization and parenteral antimicrobial therapy. SE-TU Study Group. Clin Infect Dis 1998;27:566-72.

20. Davies HD, Matlow A, Petric M, Glazier R, Wang EE. Prospective comparative study of viral, bacterial and atypical organisms identified in pneumonia and bronchiolitis in hospitalized Canadian infants. Pediatr Infect Dis J 1996;15:371-5.

21. Correa AG, Starke JR. Infections of the lower respiratory tract in children. In: Niederman MS, Sarosi GA, Glassroth J, eds. Respiratory Infections. Philadelphia: Lippincott Williams and Wilkins, 2001:155-80.

22. McIntosh K. Community-acquired pneumonia in children. N Engl J Med 2002;346:429-37.

23. Korppi M, Heiskanen-Kosma T, Jalonen E, et al. Aetiology of community-acquired pneumonia in children treated in hospital. Eur J Pediatr 1993;152:24-30.

24. Scheifele D, Gold R, Law B, et al. Decline in Haemophilus influenzae type B invasive infections at five Canadian pediatric centres. Can Commun Dis Rep 1993;19:88-91.

25. Scheifele D, Halperin S. Haemophilus influenzae type B disease control using PENTACEL, Canada, 1998-1999. Can Commun Dis Rep 2000;26:93-6.

26. Scheifele D, Halperin S, Vaudry W, et al. Historic low Haemophilus influenzae type B case tally - Canada 2000. Can Commun Dis Rep 2001;27:149-50.

27. Paisley JW, Lauer BA, McIntosh K, Glode MP, Schachter J, Rumack C. Pathogens associated with acute lower respiratory tract infection in young children. Pediatr Infect Dis $1984 ; 3: 14-9$ 
28. Pandey A, Chaudhry R, Nisar N, Kabra SK. Acute respiratory tract infections in Indian children with special reference to Mycoplasma pneumoniae. J Trop Pediatr 2000;46:371-4.

29. Esposito S, Bosis S, Cavagna R, et al. Characteristics of Streptococcus pneumoniae and atypical bacterial infections in children $2-5$ years of age with community-acquired pneumonia. Clin Infect Dis 2002;35:1345-52.

30. Heiskanen-Kosma T, Korppi M, Laurila A, Jokinen C, Kleemola M, Saikku P. Chlamydia pneumoniae is an important cause of community-acquired pneumonia in school-aged children: Serological results of a prospective, population-based study. Scand J Infect Dis 1999;31:255-9.

31. Nobert E, Chernick V. Tuberculosis: 5. Pediatric disease. CMAJ 1999;160:1479-82.

32. Margolis PA, Ferkol TW, Marsocci S, et al. Accuracy of the clinical examination in detecting hypoxemia in infants with respiratory illness. J Pediatr 1994;124:552-60.

33. Leventhal JM. Clinical predictors of pneumonia as a guide to ordering chest roentgenograms. Clin Pediatr (Phila) 1982;21:730-4

34. Taylor JA, Del Beccaro M, Done S, Winters W. Establishing clinically relevant standards for tachypnea in febrile children younger than 2 years. Arch Pediatr Adolesc Med $1995 ; 149: 283-7$.

35. Palafox M, Guiscafre H, Reyes $\mathrm{H}$, Munoz O, Martinez $\mathrm{H}$. Diagnostic value of tachypnoea in pneumonia defined radiologically. Arch Dis Child 2000;82:41-5.

36. World Health Organization. Acute respiratory infections in children: Case management in small hospitals in developing countries. In: WHO, ed. WHO/ARI/90.5. Geneva: 1990.

37. Berman S, Simoes EA, Lanata C. Respiratory rate and pneumonia in infancy. Arch Dis Child 1991;66:81-4.

38. Margolis P, Gadomski A. Does this infant have pneumonia? JAMA 1998;279:308-13.

39. Zukin DD, Hoffman JR, Cleveland RH, Kushner DC, Herman TE. Correlation of pulmonary signs and symptoms with chest radiographs in the pediatric age group. Ann Emerg Med 1986; 15:792-6

40. Wang EE, Milner RA, Navas L, Maj H. Observer agreement for respiratory signs and oximetry in infants hospitalized with lower respiratory infections. Am Rev Respir Dis 1992;145:106-9.

41. Bachur R, Perry H, Harper MB. Occult pneumonias: Empiric chest radiographs in febrile children with leukocytosis. Ann Emerg Med 1999;33:166-73.

42. Ravichandran D, Burge DM. Pneumonia presenting with acute abdominal pain in children. Br J Surg 1996;83:1707-8.

43. Jona JZ, Belin RP. Basilar pneumonia simulating acute appendicitis in children. Arch Surg 1976;111:552-3.

44. Swingler GH, Hussey GD, Zwarenstein M. Randomised controlled trial of clinical outcome after chest radiograph in ambulatory acute lower-respiratory infection in children. Lancet 1998;351:404-8.

45. Bushyhead JB, Wood RW, Tompkins RK, Wolcott BW, Diehr P. The effect of chest radiographs on the management and clinical course of patients with acute cough. Med Care 1983;21:661-73.

46. Alario AJ, McCarthy PL, Markowitz R, Kornguth P, Rosenfield $\mathrm{N}$, Leventhal JM. Usefulness of chest radiographs in children with acute lower respiratory tract disease. J Pediatr 1987;111:187-93.

47. Bachur R, Perry H, Harper M. Empiric chest radiographs in febrile children with leukocytosis. Ann Emerg Med 1999;33:480

48. Kramer MS, Roberts-Brauer R, Williams RL. Bias and 'overcall' in interpreting chest radiographs in young febrile children. Pediatrics 1992;90:11-3.

49. Green SM, Rothrock SG. Evaluation styles for well-appearing febrile children: are you a "risk-minimizer" or a "test-minimizer"? Ann Emerg Med 1999;33:211-4.

50. Young M, Marrie TJ. Interobserver variability in the interpretation of chest roentgenograms of patients with possible pneumonia. Arch Intern Med 1994;154:2729-32.

51. Tew J, Calenoff L, Berlin BS. Bacterial or nonbacterial pneumonia: Accuracy of radiographic diagnosis. Radiology 1977;124:607-12.

52. Swingler GH. Radiologic differentiation between bacterial and viral lower respiratory infection in children: A systematic literature review. Clin Pediatr (Phila) 2000;39:627-33.

53. Roback MG, Dreitlein DA. Chest radiograph in the evaluation of first time wheezing episodes: Review of current clinical practice and efficacy. Pediatr Emerg Care 1998;14:181-4.

54. Heaton P, Arthur K. The utility of chest radiography in the follow-up of pneumonia. N Z Med J 1998;111:315-7.

55. Silverman M, Stratton D, Diallo A, Egler LJ. Diagnosis of acute bacterial pneumonia in Nigerian children. Value of needle aspiration of lung of countercurrent immunoelectrophoresis. Arch Dis Child 1977;52:925-31.

56. Vuori-Holopainen E, Peltola H. Reappraisal of lung tap: Review of an old method for better etiologic diagnosis of childhood pneumonia. Clin Infect Dis 2001;32:715-26.

57. Hickey RW, Bowman MJ, Smith GA. Utility of blood cultures in pediatric patients found to have pneumonia in the emergency department. Ann Emerg Med 1996;27:721-5.

58. Hardie W, Bokulic R, Garcia VF, Reising SF, Christie CD. Pneumococcal pleural empyemas in children. Clin Infect Dis 1996;22:1057-63.

59. Shuttleworth DB, Charney E. Leukocyte count in childhood pneumonia. Am J Dis Child 1971;122:393-6.

60. Ghildyal R, Hogg G, Meanger J. Detection and subgrouping of respiratory syncytial virus directly from nasopharyngeal aspirates. Clin Microbiol Infect 1997;3:120-3.

61. Skerrett SJ. Diagnostic testing for community-acquired pneumonia. Clin Chest Med 1999;20:531-48.

62. Heiskanen-Kosma T, Korppi M, Jokinen C, et al. Etiology of childhood pneumonia: Serologic results of a prospective, population-based study. Pediatr Infect Dis J 1998;17:986-91.

63. McCracken GH Jr. Diagnosis and management of pneumonia in children. Pediatr Infect Dis J 2000;19:924-8.

64. Bradley JS. Management of community-acquired pediatric pneumonia in an era of increasing antibiotic resistance and conjugate vaccines. Pediatr Infect Dis J 2002;21:592-8.

65. Hall CB, Powell KR, Schnabel KC, Gala CL, Pincus PH. Risk of secondary bacterial infection in infants hospitalized with respiratory syncytial viral infection. J Pediatr 1988;113:266-71.

66. Esposito S, Blasi F, Arosio C, et al. Importance of acute Mycoplasma pneumoniae and Chlamydia pneumoniae infections in children with wheezing. Eur Respir J 2000;16:1142-6.

67. Zhanel GG, Karlowsky JA, Palatnick L, Vercaigne L, Low DE, Hoban DJ. Prevalence of antimicrobial resistance in respiratory tract isolates of Streptococcus pneumoniae: Results of a Canadian national surveillance study. The Canadian Respiratory Infection Study Group. Antimicrob Agents Chemother 1999;43:2504-9.

68. Kellner JD, Ford-Jones EL. Streptococcus pneumoniae carriage in children attending 59 Canadian child care centers. Toronto Child Care Centre Study Group. Arch Pediatr Adolesc Med 1999;153:495-502.

69. Scheifele D, Halperin S, Pelletier L, Talbot J. Invasive pneumococcal infections in Canadian children, 1991-1998: Implications for new vaccination strategies. Canadian Paediatric Society/Laboratory Centre for Disease Control Immunization Monitoring Program, Active (IMPACT). Clin Infect Dis 2000;31:58-64

70. Davidson RJ, Canadian Bacterial Surveillance Network, Low DE. A cross Canada survillance of antimicrobial resistance in respiratory tract pathogens. Can J Infect Dis 1999;10:128-33

71. Kaplan SL, Mason EO Jr, Wald E, et al. Six year multicenter surveillance of invasive pneumococcal infections in children. Pediatr Infect Dis J 2002;21:141-7.

72. Chen D, McGeer A, de Azavedo JC, Low DE, The Canadian Bacterial Surveillance Network. Decreased susceptibility of Streptococcus pneumoniae to fluoroquinolones in Canada. N Engl J Med 1999;341:233-9. 
73. Low DE. Antimicrobial drug use and resistance among respiratory pathogens in the community. Clin Infect Dis 2001;33(Suppl 3):S206-13.

74. Zhanel GG, Karlowsky JA, Low DE, Hoban DJ. Antibiotic resistance in respiratory tract isolates of Haemophilus influenzae and Moraxella catarrhalis collected from across Canada in 1997 1998 [In Process Citation]. J Antimicrob Chemother 2000;45:655-62.

75. Block S, Hedrick J, Hammerschlag MR, Cassell GH, Craft JC. Mycoplasma pneumoniae and Chlamydia pneumoniae in pediatric community-acquired pneumonia: Comparative efficacy and safety of clarithromycin vs. erythromycin ethylsuccinate. Pediatr Infect Dis J 1995;14:471-7.
76. Harris JA, Kolokathis A, Campbell M, Cassell GH, Hammerschlag MR. Safety and efficacy of azithromycin in the treatment of community-acquired pneumonia in children. Pediatr Infect Dis J 1998;17:865-71.

77. Fine MJ, Auble TE, Yealy DM, et al. A prediction rule to identify low-risk patients with community-acquired pneumonia [see comments]. N Engl J Med 1997;336:243-50.

78. Klein JO. Bacterial pneumonias. In: Feigin RD, Cherry JD, eds. Textbook of Pediatric Infectious Diseases. Philadelphia: WB Saunders Company, 1998:274-84.

79. Eigen H, Laughlin JJ, Homrighausen J. Recurrent pneumonia in children and its relationship to bronchial hyperreactivity. Pediatrics 1982;70:698-704. 


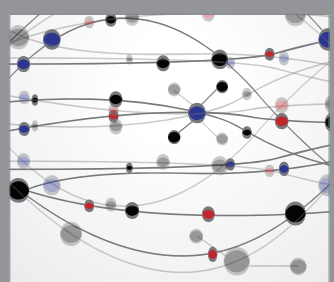

The Scientific World Journal
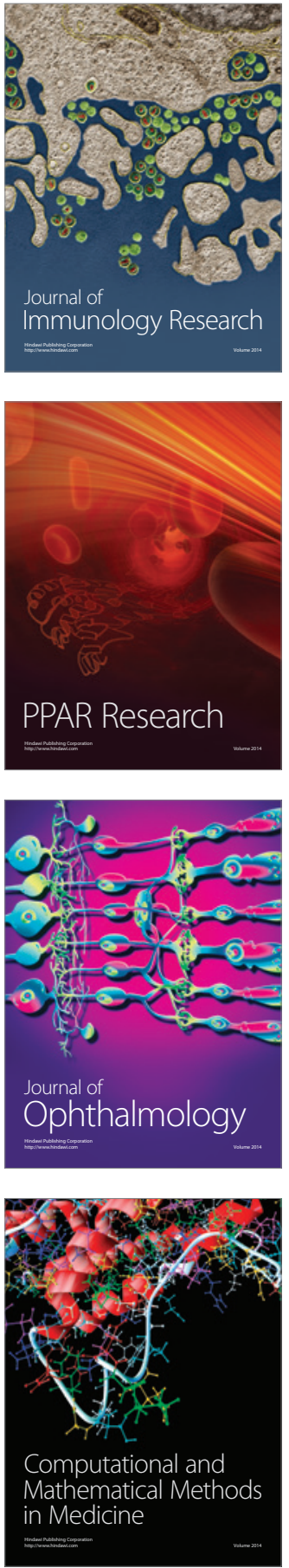

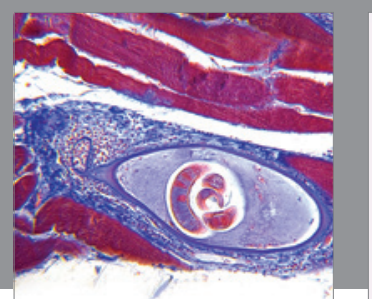

Gastroenterology Research and Practice

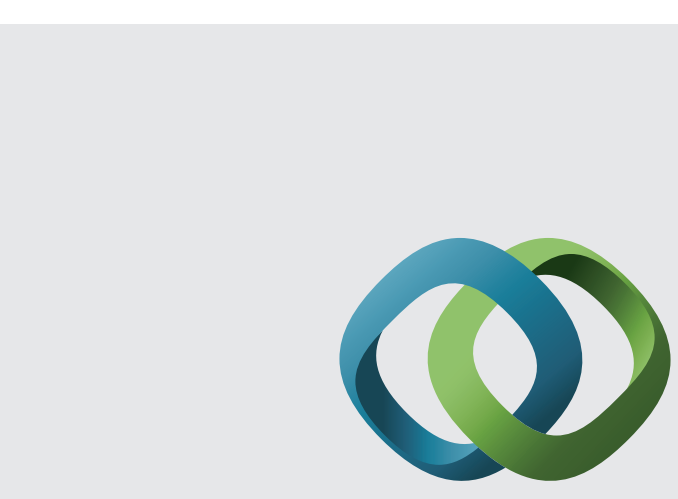

\section{Hindawi}

Submit your manuscripts at

http://www.hindawi.com
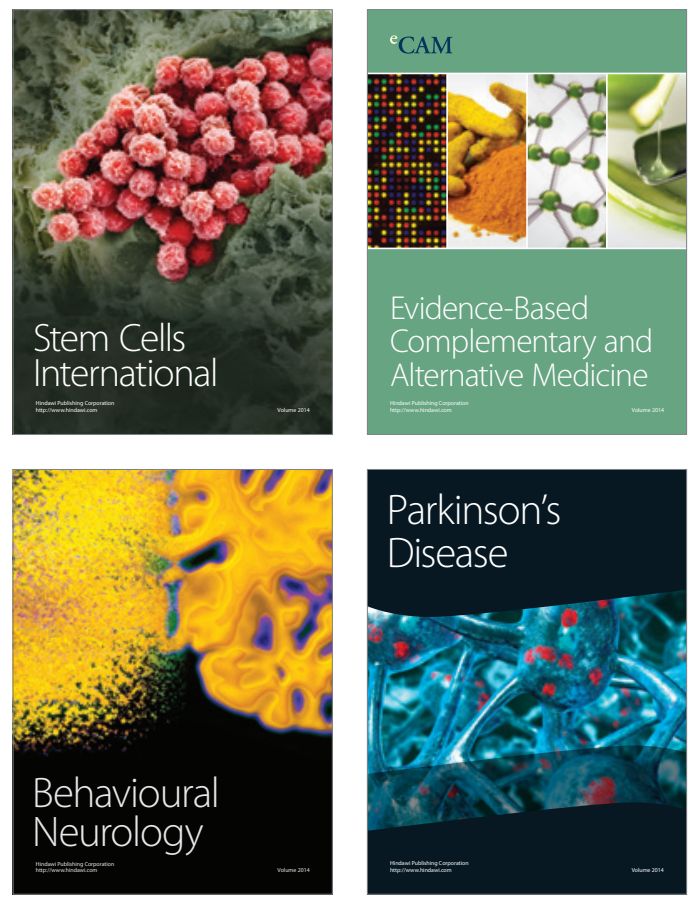
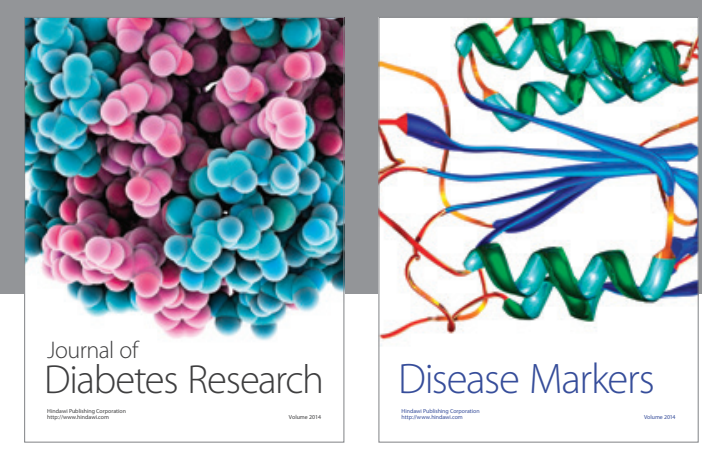

Disease Markers
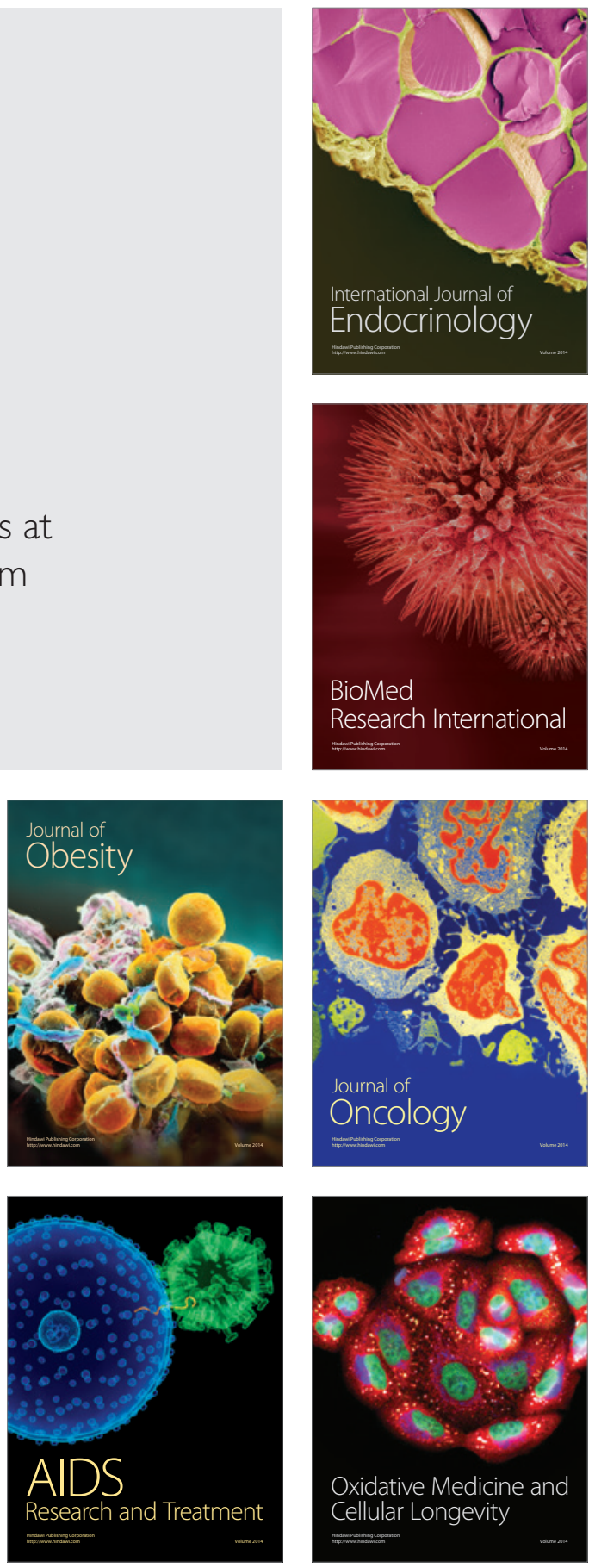